\title{
MICROSTRUCTURE AND MECHANICAL PROPERTIES OF ALUMINIUM BACK CONTACT LAYERS
}

\author{
V.A. Popovich ${ }^{1}$, M. Janssen ${ }^{1}$, I.M. Richardson ${ }^{1}$, T. van Amstel $^{2}$, I. J. Bennett ${ }^{2}$ \\ 1. Delft University of Technology, Department of Materials Science \& Engineering, Delft, The Netherlands, \\ Phone: +31 (0) 1527895 68, email: v.popovich@tudelft.nl \\ 2. Energy Research Centre of the Netherlands, Solar Energy, PV Module Technology, Petten, The Netherland
}

\begin{abstract}
The overall demand to reduce solar energy costs gives a continuous drive to reduce the thickness of silicon wafers. Handling and bowing problems associated with thinner wafers become more and more important, as these can lead to cells cracking and thus to high yield losses. In this paper the microstructure and mechanical properties of the aluminium on the rear side of a solar cell are discussed. It is shown that the aluminium back contact has a complex composite-like microstructure, consisting of five main components: 1) the back surface field layer; 2) a eutectic layer; 3) spherical (3 - $5 \mu \mathrm{m})$ hypereutectic Al-Si particles surrounded by a thin aluminum oxide layer $(200 \mathrm{~nm})$; 4) a bismuth-silicate glass matrix; and 5) pores (14 vol.\%). The Young's modulus of the Al-Si particles is estimated by nanoindentation and the overall Young's modulus is estimated on the basis of bowing measurements. These results are used as input parameters for an improved thermomechanical multiscale model of a silicon solar cell. Keywords: Al back contact, Young's modulus, bowing, silicon solar cell
\end{abstract}

\section{INTRODUCTION}

The most critical processing step during the manufacture of screen-printed solar cells is the firing process. Residual stresses are formed within the cell due to mismatch of thermal expansion coefficients and different mechanical behaviour of the materials used in the metallic contacts. The wafer bows and forms a convex or concave body upon cooling, which mechanically loads the cell and may cause fracture [1].

As the thickness of silicon wafers is reduced, cell bowing becomes a major problem during different processing steps. It is possible to decrease bowing by reducing the amount of aluminium paste or by changing the paste chemistry and firing conditions. However, there is a limit below which screen-printed aluminium paste will lead to a non-uniform back surface field layer, influencing the electrical properties of the cell [2-4]. Nowadays it is very important to find a compromise between electrical properties, strength and costs of the solar cell. To achieve this, it is necessary to have a better understanding of microstructure, stress development and mechanical properties of the cell.

In this paper an investigation is reported of the microstructure and mechanical properties of the aluminium at the rear side of the solar cell, and on the effect of the paste composition on bowing. On the basis of this knowledge it should be possible to better determine mechanical limits of the solar cell, with the aim of reducing yield losses during cell and module manufacture.

\section{EXPERIMENTAL CONDITIONS}

Silicon wafers of a constant thickness $(200 \mu \mathrm{m})$ were sliced off a single multicrystalline silicon block. In our study only wafers from the middle of the block contributed to the results. A standard industrial cell process was used in this research. The screen printing of the rear was performed with a conventional screen printer and a 165 mesh screen. To examine the influence of the composition of the aluminium paste on bowing, three different commercially available aluminum pastes were used (pastes A, B and C).

Measurements of the curvature were done by an optical method, using a Quick Vision Mitutoyo system. Five neighboring cells were prepared for each type of $\mathrm{Al}$ paste. Measurements were performed over the full length of the solar cell $(156 \mathrm{~mm})$.

A JEOL JSM 6500F scanning electron microscope (SEM) with energy-dispersive spectroscopy (EDS) was used for microstructural analysis of cleaved samples from a conventional H-pattern solar cell. In order to identify the $\mathrm{Al}-\mathrm{Si}$ reaction layer, samples were polished and etched in a solution of $\mathrm{HF}-\mathrm{HNO}_{3}-\mathrm{CH}_{3} \mathrm{COOH}$ (1:3:6) for 20 seconds. Metallic polishing holders were used to prevent any influence of the embedding resin on the microstructure analysis. Apart from EDS, the composition was determined by electron probe microanalysis (EPMA), which will not be presented in detail in this paper.

Phase identification of the as-dried and sintered $\mathrm{Al}$ pastes was conducted by X-ray diffraction using a D8discover diffractometer $\left(\mathrm{Cu} \mathrm{K}_{\alpha}\right.$ radiation) equipped with an Euler cradle. A multiphase structure refinement was carried out by means of a full profile Rietveld method including refinement of the lattice parameters, atomic positions, scale factor, zero shift, background and Braggpeak profile parameters. Starting models for the calculation procedure were taken from the inorganic crystal structure database (ICSD) [5].

High-resolution computed tomography was performed with a "Nanotom" system equipped with a high-power nanofocused tube $(180 \mathrm{kV} / 15 \mathrm{~W})$ for a microstructural characterization of the as fired aluminium bulk layer, namely, concentration profile determination of glass phases in the as-fired aluminium paste, as well as a porosity investigation. This technique provides a three- 
dimensional spatial image of an object, distinguishing different materials on the basis of their density. Computed tomography 3D images were generated by rotation of the sample over $360^{\circ}$ with a step size of $0.5^{\circ}$ around an axis (perpendicular to the solar cell surface), while taking a series of $2 \mathrm{D}$ pictures. Afterwards these images were combined to create a $3 \mathrm{D}$ volumetric representation of the structure using a reconstruction algorithm.

Mercury intrusion porosimetry (MIP) was performed on small $(30 \times 10 \mathrm{~mm})$ samples to determine the porosity and the pore size distribution in the $\mathrm{Al}$ rear face layer. This technique is based on the principle that mercury is a non-wetting liquid and requires a force to penetrate voids. The experiments were performed on a $\mathrm{CE}$ instrument Pascal 140 (low pressure) and Pascal 440 (high pressures) in a pressure range from $0.01 \mathrm{kPa}$ to 2 MPa.

Elastic properties of solar cell cross section layers were characterized by a nanoindentation technique using an MT5 Nanoindenter G200 instrument, capable of continuous stiffness measurements. For these experiments, samples were embedded into an Epofix resin for a better support during indentation. The tester was equipped with a three-side pyramid (Berkovich) diamond indenter with a $50 \mathrm{~nm}$ tip radius.

Nanoindentation results were averaged over 30 indentations, made for every sample. The Young's modulus was evaluated according to the Oliver and Pharr approach [6].

\section{RESULTS AND DISCUSSION}

Fig. 1(a) shows a polished and etched SEM cross section of a typical screen printed silicon solar cell microstructure consisting of 5 distinct layers: silver, silicon, back surface field (BSF), eutectic and bulk aluminum. The bulk aluminum layer was found to have a complex porous microstructure. A closer look into the bulk $\mathrm{Al}$ layer (Fig. 1 (b)) reveals the presence of spherical particles, surrounded by a distinct oxide layer. The thickness of this oxide layer is about $150-200 \mathrm{~nm}$, which is in good agreement with TGA experiments (not presented here) showing (partial) oxidation of the aluminum in the sample by a mass increase around $600{ }^{\circ} \mathrm{C}$. Electron probe microanalysis confirmed an increase of oxygen concentration around the particle edges.

This oxide layer creates a shell around the particle, which holds the particles in place, and thus creates a stable microstructure of the paste. It is expected that a particle-to-particle contact is made by the oxide layer, which might lead to only a weak bond between the particles, negatively affecting the mechanical properties of the layer. EDS results showed that these spherical particles have a nearly eutectic Al-Si composition, surrounded by a complex matrix of $\mathrm{Al}, \mathrm{Si}$ and $\mathrm{O}$ (Fig. 2). $\mathrm{X}$-ray element mapping also showed the presence of $\mathrm{Bi}$ and $\mathrm{Ca}$, which is a residue from the initial $\mathrm{Al}$ paste.

An XRD analysis was performed on the back surface of the cell in order to indentify phases present in the $\mathrm{Al}$ layer. Measurements were done for both a mechanically removed $\mathrm{Al}$ layer and an as-processed layer on top of a $\mathrm{Si}$ wafer. Fig. 3 shows the X-ray spectrum of the Al paste, mechanically removed after firing.

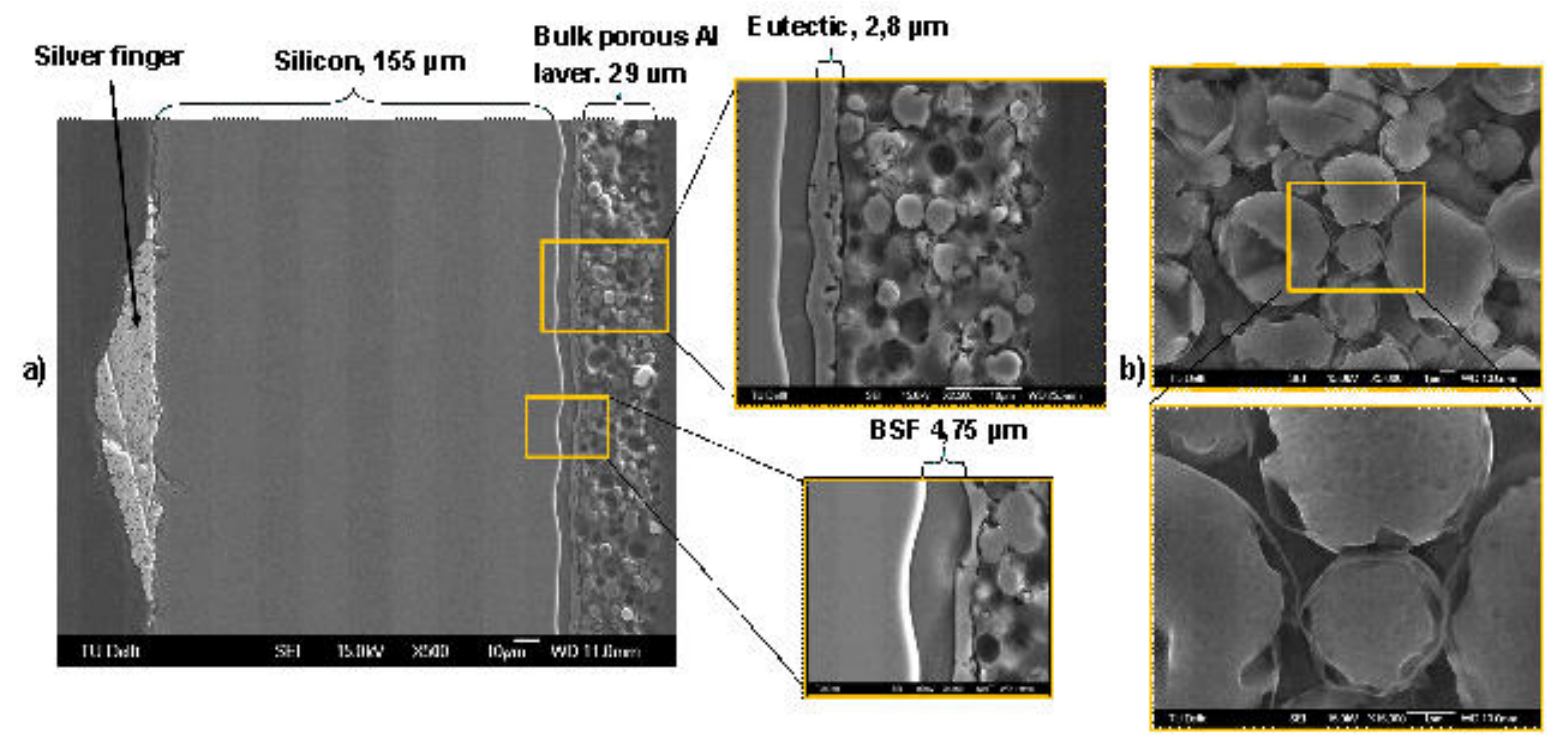

Figure 1. (a) SEM micrograph of cross section of a conventional silicon solar cell $\left(156 \times 156 \mathrm{~mm}^{2}, 200 \mu \mathrm{m}\right)$, comprising 5 distinct layers; b) Microstructure of bulk Al layer with Al-Si spherical particles, surrounded by a thin film of alumina. 


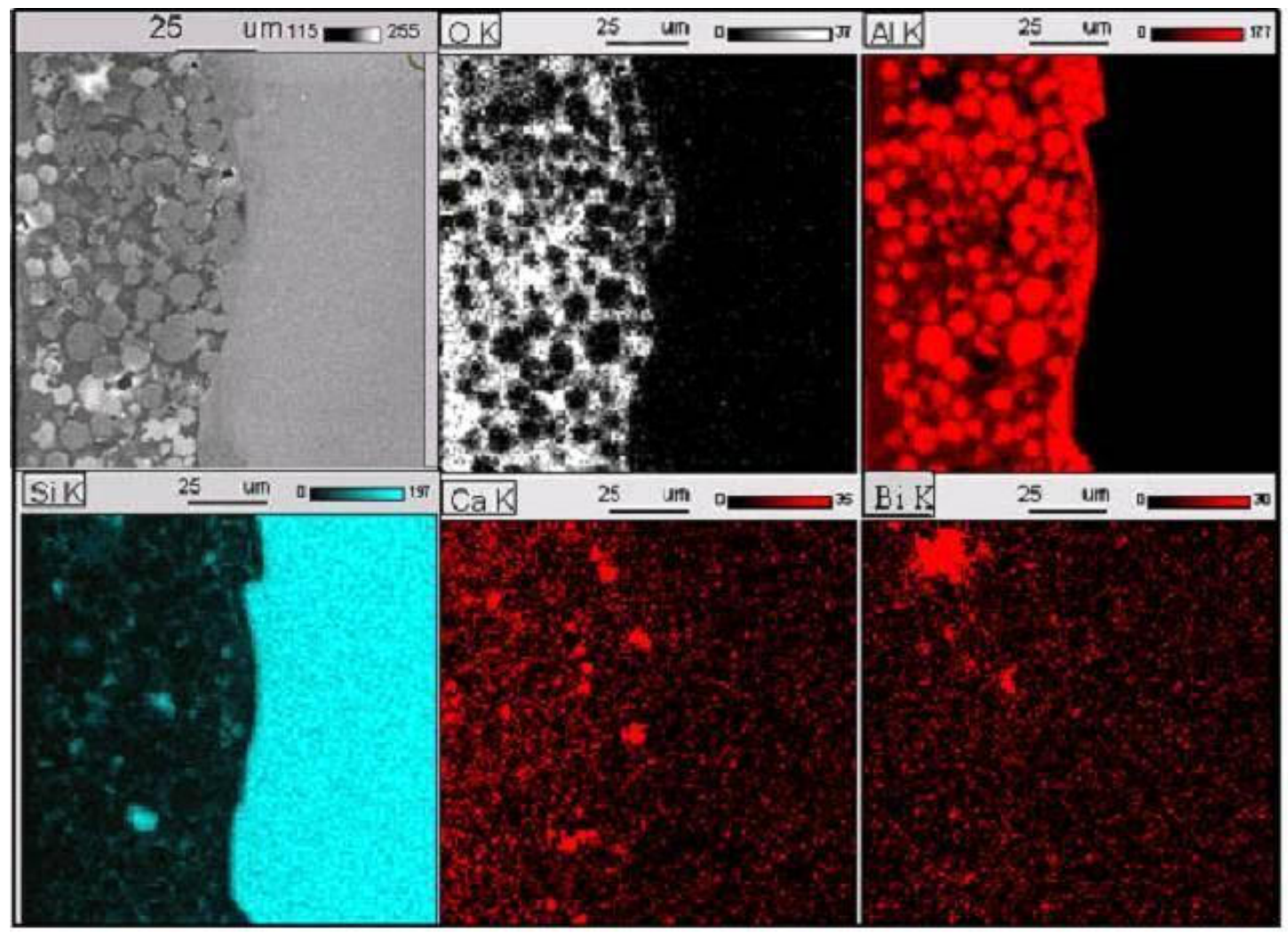

Figure 2. X-ray element mapping of cross section of the Al-Si layer, indicating the distribution of selected elements.

Besides the expected $\mathrm{Al}$ and $\mathrm{Si}$, three extra phases were detected, namely $\gamma-\mathrm{Al}_{2} \mathrm{O}_{3}, \mathrm{CaMgSiO}_{4}$, and bismuth silicon oxide. The latter two are a residue of the initial glass frit present in the $\mathrm{Al}$ paste to obtain better sintering properties of the contact layer. The presence of $\gamma-\mathrm{Al}_{2} \mathrm{O}_{3}$ is in good agreement with literature results, showing a formation of amorphous alumina between 300 to $550{ }^{\circ} \mathrm{C}$ and its further transformation into $\gamma-\mathrm{Al}_{2} \mathrm{O}_{3}$ at about $550^{\circ} \mathrm{C}[7]$.

In order to evaluate the ratio between $\mathrm{Al}$ and $\mathrm{Si}$ in the $\mathrm{Al}$ back surface layer a full profile Rietveld refinement was performed, employing FullProf software. As a starting model for the refinement, bulk $\mathrm{Al}$ and $\mathrm{Si}$ structures were used; glass phases were not included in the refinement. The refinement provided good agreement between observed and calculated profiles. The estimated weight ratio between $\mathrm{Al}$ and $\mathrm{Si}$, e.g. $83 \%: 17 \%$ is found to be in a good agreement with EDS/EPMA results.

A computer tomography analysis was carried out to obtain the amount and distribution of bismuth silicate glass and porosity. Fig. 4, (a) shows a representative 2D $\mathrm{X}$-ray image of the $\mathrm{Al}$ layer (paste B). The yellow parts correspond to a higher atomic number material (bismuth, $Z=83$ ), which absorbs more $X$-rays, and the grey parts to lower atomic number materials, such as aluminum $(Z=13)$ and silicon $(Z=14)$. Based on the digital 3D images of Fig. 4(b), the fraction of bismuth glass and of porosity in paste B was estimated to be 3.9 vol. \% and 14 vol. \%, respectively. Results on the other pastes are presented in Table 1.

The overall open porosity of the Al layer, estimated by mercury intrusion porosimetry, was found to be around $15 \%$, which is in good agreement with computed tomography results. Mercury intrusion showed that at a relatively low pressure $(0.06 \mathrm{MPa})$ filling of large pores (around 50 microns) occurs. An increase in pressure (0.5-2 MPa) revealed the filling of the remaining small pores, which are about 2 microns in size.

Fig. 5 shows a representative nanoindentation loaddisplacement curve and SEM micrograph of the nanoindented Al-Si particle. The Young's modulus of the bulk layer particles was found to be approximately $72 \mathrm{GPa}$ at $1.5 \mathrm{mN}$, which agrees well with literature results for eutectic Al-Si alloys [8]. However, this value is not representative for the elastic modulus of the porous Al layer as a whole. 


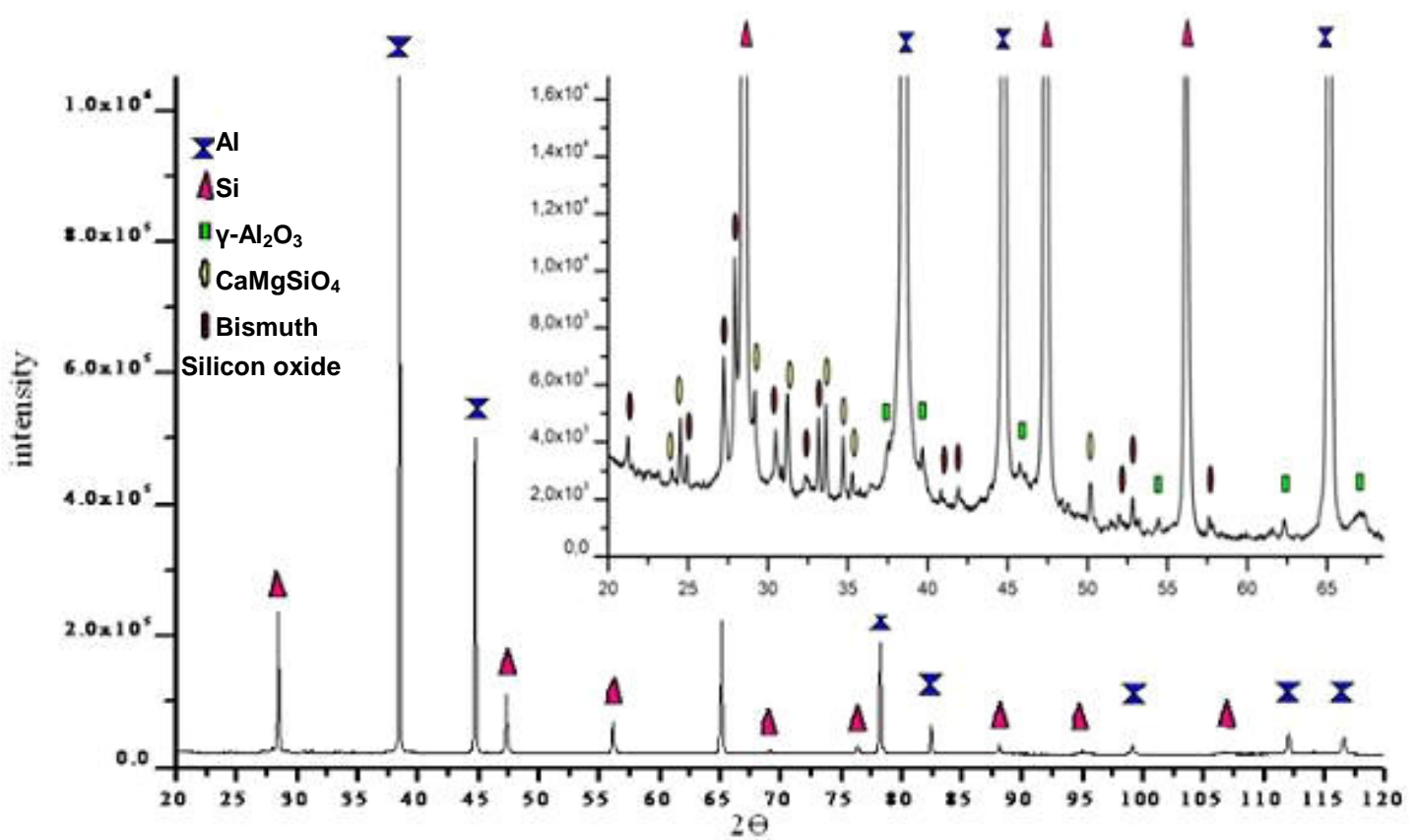

Figure 3. XRD spectrum of the mechanically removed $\mathrm{Al}$ paste after firing. Inset shows an enlarged fragment of the XRD pattern from $2 \theta=20^{\circ}$ to $68^{\circ}$.

It is known, that bowing of material layers in contact with each other having different thermal expansion coefficients ( $\mathrm{Si}$ and $\mathrm{Al}$ in our case) can be represented by a bimetallic strip model, assuming bending in only one dimension [3].

If only elastic deformation occurs, the resulting amount of bowing, $\delta$, can be calculated using

$$
\delta=\frac{3\left(\alpha_{b}-\alpha_{t}\right)\left(T_{f}-T_{m}\right)\left(t_{b}+t_{t}\right) L^{2}}{4 t_{b}^{2}\left(4+6 \frac{t_{t}}{t_{b}}+4\left(\frac{t_{t}}{t_{b}}\right)^{2}+\left(\frac{E_{t}}{E_{b}}\right)\left(\frac{t_{t}}{t_{b}}\right)^{3}+\left(\frac{E_{b}}{E_{t}}\right)\left(\frac{t_{b}}{t_{t}}\right)\right)},
$$

where $t_{\mathrm{t}}$ is the thickness of the top component, $t_{\mathrm{b}}$ is the thickness of the bottom component, $\alpha_{\mathrm{t}}$ is the thermal coefficient of expansion (TCE) of the top component, $\alpha_{\mathrm{b}}$ is the TCE of the bottom component, $T_{\mathrm{f}}$ is the firing temperature (contact formation temperature, $577{ }^{\circ} \mathrm{C}$ ), $T_{\mathrm{m}}$ is the measuring temperature (room temperature), $E_{\mathrm{t}}$ is the elastic modulus of the top component ( $\mathrm{Si}$ wafer), $E_{\mathrm{b}}$ is the elastic modulus of the bottom component (Al layer) and $L$ is the length of the cell.
Using experimentally obtained bowing results and the above formula, it was possible to recalculate the overall elastic modulus of the $\mathrm{Al}$ contact layer, which was found to be around $43 \mathrm{GPa}$, (as an average of three different aluminum pastes). However, the bimetallic strip model accounts only for a two layers system, thus the obtained value of young's modulus should be considered as an average of that of the porous $\mathrm{Al}$ layer and of the eutectic layer.

Table 1, shows the influence of the paste composition on bowing and clearly demonstrates that the paste composition has a large impact on the Young's modulus of the fired aluminum paste.

As can be seen, there is a correlation between the aluminum paste composition (porosity and bismuth glass concentration), bowing and Young's modulus. A more detailed investigation on the relation between these parameters is out of the scope of this paper and will be presented in a follow-up article. 
a)

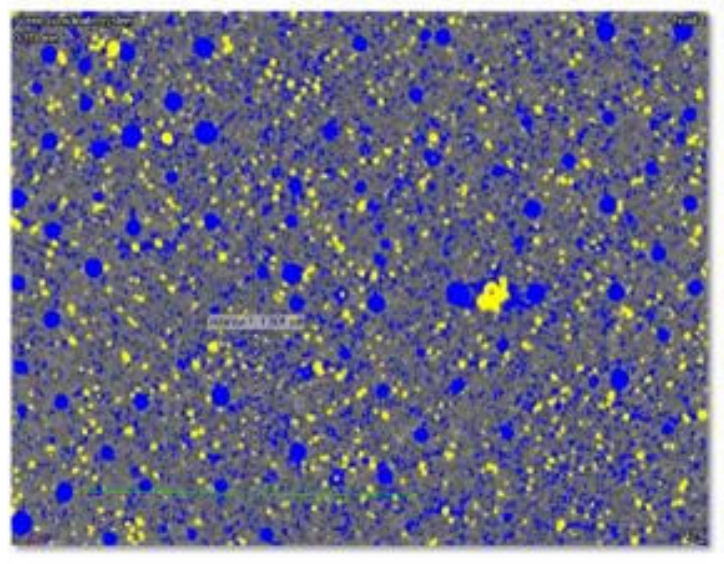

b)
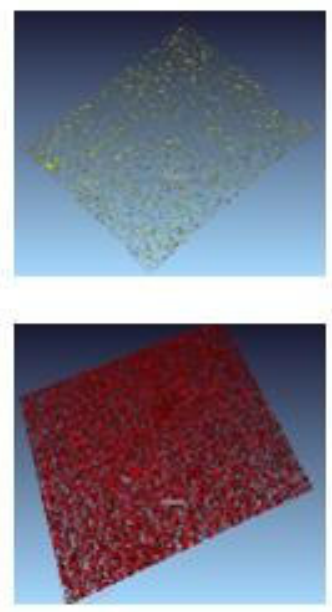

Figure 4. a) 2D X-ray image of the Al layer (Paste B), showing the differences in photographic density between different parts (yellow part: bismuth, blue: porosity, grey: $\mathrm{Al}$ and $\mathrm{Si}$ ). b) 3D volumetric representation of bismuth glass phase (upper) and porosity (lower) distributions.

Table 1. Correlation between aluminium paste composition, bowing and Young's modulus of the fired aluminum rear side contact.

\begin{tabular}{|c|c|c|c|c|}
\hline $\begin{array}{c}\text { Paste } \\
\text { type }\end{array}$ & $\begin{array}{c}\text { Porosity, } \\
\%\end{array}$ & $\begin{array}{c}\text { Bismuth } \\
\text { glass, \% }\end{array}$ & $\begin{array}{c}\text { Bowing } \\
\text { over } \\
150 \mathrm{~mm}, \\
\mathrm{~mm}\end{array}$ & $\begin{array}{c}\text { Young's } \\
\text { Modulus, } \\
\text { GPa }\end{array}$ \\
\hline A & 10.9 & 1.8 & 1.4 & 41 \\
\hline B & 14 & 3.9 & 2.6 & 44 \\
\hline C & 16 & 4.2 & 1.8 & 46 \\
\hline
\end{tabular}

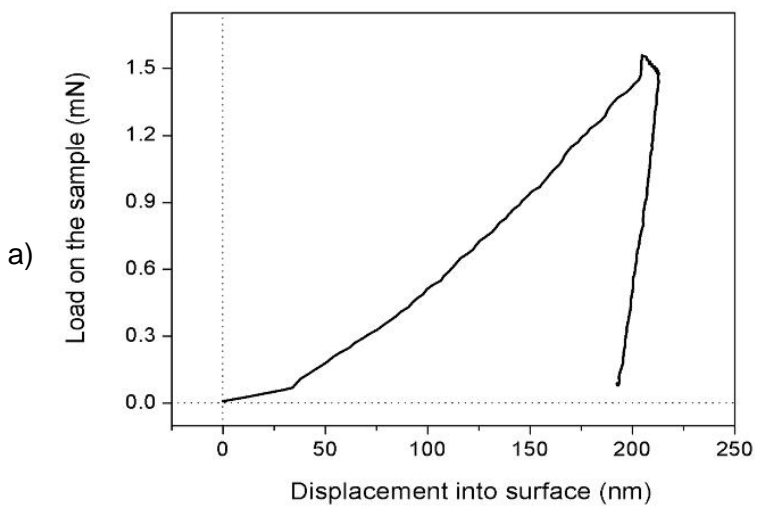

Based on the results presented here, a model was made describing the cross section of the rear face of the silicon solar cell with corresponding microstructure features (Fig. 6). The $\mathrm{Al}$ layer is represented as a complex composite-like material, consisting of three main components: 1) spherical (3 - $5 \mu \mathrm{m})$ hypereutectic Al-Si particles, surrounded by a thin aluminum oxide layer $(200 \mathrm{~nm}) ; 2)$ a bismuth-silicate glass matrix (3.3 vol. \%, as an average of different $\mathrm{Al}$ pastes); 3 ) pores (14 vol.\%).

The results of microstructure, nanoindentation analyses and bowing measurements are used in a thermomechanical multiscale model of a solar cell. The model integrates the thermomechanical behaviour of the layers at the rear of the cell, allowing bowing of the whole cell to be predicted [9]

b)

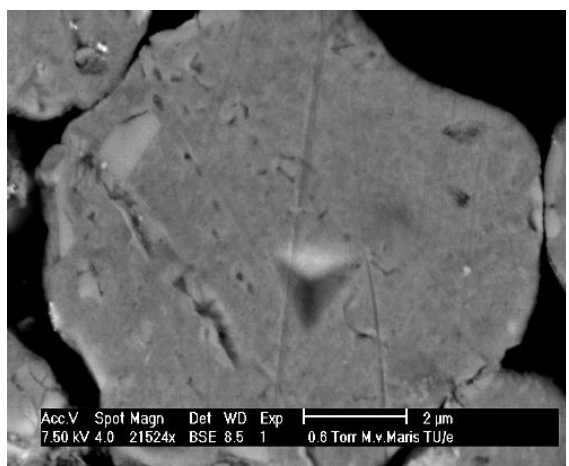

Figure 5. a) Load-displacement curve and b) SEM micrograph of representative nanoindented Al-Si particle. 


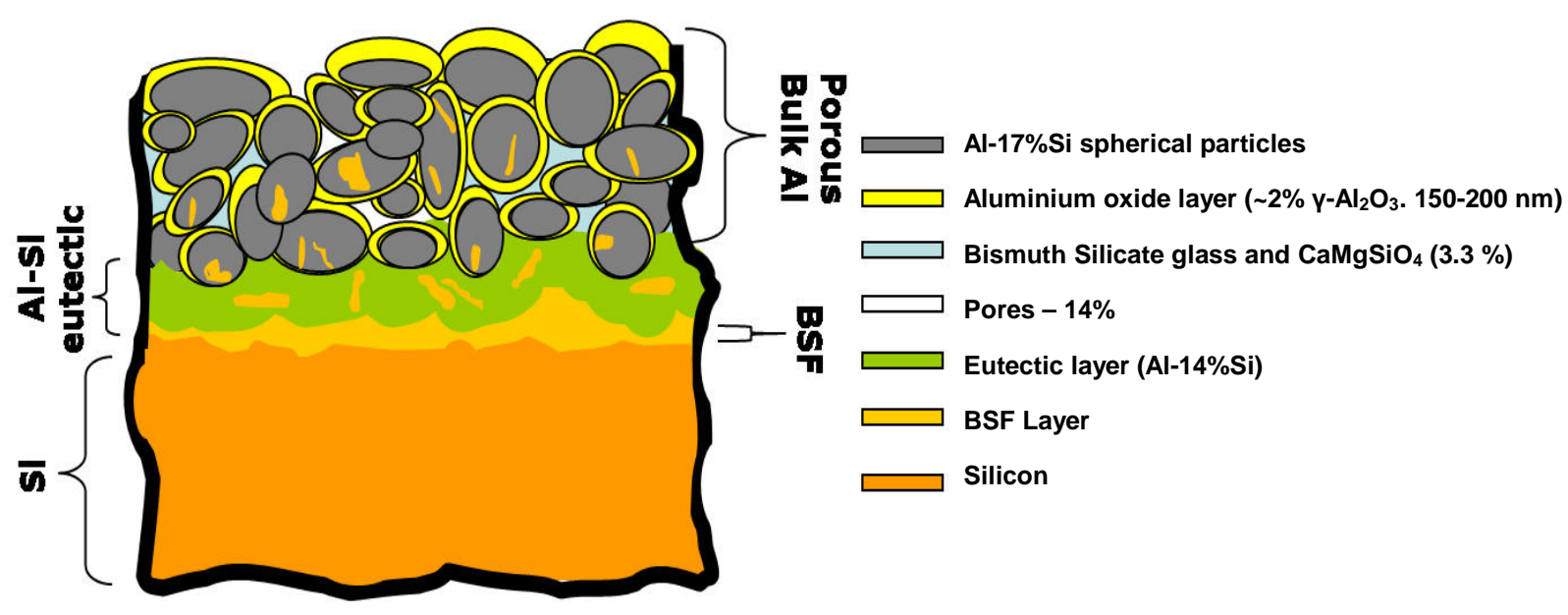

Figure 6. Model of the rear face of a silicon solar cell with corresponding microstructure features.

\section{CONCLUSIONS}

In this work the microstructure and mechanical properties of the aluminum on the rear face of a solar cell were investigated. It was shown that the bulk $\mathrm{Al}$ layer has a complex composite-like microstructure, consisting of three main components: 1) spherical (3 - $5 \mu \mathrm{m})$ hypereutectic Al-Si particles, surrounded by a thin aluminum oxide layer (150-200 $\mathrm{nm}) ; 2)$ a bismuth-silicate glass matrix (3.3\%) 3) pores (14 vol.\%). The Young's modulus of the Al-Si particles, obtained by nanoindentation, was found to be $72 \mathrm{GPa}$. However, the overall Young's modulus of the $\mathrm{Al}$ rear side contact (including bulk Al layer and eutectic layer), estimated by a bimetallic strip model and bowing measurements, was found to be about $43 \mathrm{GPa}$. These results are used as input parameters for an improved thermomechanical multiscale model of a silicon solar cell, which incorporates the behavior of the various layers.

\section{REFERENCES}

[1] T van Amstel, V.A. Popovich, P. C. de Jong \& I. G. Romijn, "Modeling mechanical aspects of the aspire cell". In s.n. (Ed.), Proceedings of the 23rd European Photovoltaic Solar Energy Conference, Valencia, Spain, September 1-5, 2008

[2] F. Huster, "Investigation of the Alloying Process of Screen Printing Aluminum Pastes for the BSF Formation on Silicon Solar Cells", 20th European Photovoltaic Solar Energy Conference, Barcelona, 2005

[3] F. Huster, "Aluminum-back surface field: bow investigation and elimination", 20th European Photovoltaic Solar Energy Conference and Exhibition, Barcelona, 2005, pp. 635-638
[4] S. Kim et al., "Aluminum paste (Lead-Free/Low Bow) for thin wafers", IEEE $31^{\text {st }}$ Photovoltaic Specialists Conference and Exhibition, Jan. 3-7, Orlando, Florida, USA, 2004

\section{[5] http://icsdweb.fiz-karlsruhe.de/index.php}

[6] W. C. Oliver and G. M. Pharr, "An Improved Technique for Determining Hardness and Elastic Modulus Using Load and Displacement Sensing Indentation Experiments," J. Mater. Res., Vol. 7, No. 6, 1992, pp. 1564-1583

[7] M. Trunov et. al., "Effect of Polymorphic phase transformations in $\mathrm{Al}_{2} \mathrm{O}_{3}$ film on oxidation kinetics of aluminum powders", Comb. and Flame 140, 2006, pp. $310-318$

[8] M. Warmuzek, "Aluminum-Silicon casting alloys: Atlas of Micrograph", ASM International, 2004

[9] T van Amstel, V.A. Popovich, P. C. de Jong, I.J. Bennett, "A Multiscale Model of the Aluminium Layer at the Rear Side of a Solar Cell", Proceedings of the 23rd European Photovoltaic Solar Energy Conference, Hamburg, 2009 